\title{
Applications of Amberlite XAD based Chelating resins in Online Pre concentration of metal ions
}

\author{
Prem Lata Meena ${ }^{1}$ and Reena Saxena ${ }^{2}$ \\ ${ }^{I}$ Assistant Professor, Department of Polymer Science, Bhaskaracharya College of Applied Sciences, University \\ of Delhi, India, \\ ${ }^{2}$ Associate Professor, Department of Chemistry, Kirori Mal College, University of Delhi, India,
}

\begin{abstract}
An on-line preconcentration procedure for the determination of heavy metal ions using Flowinjection approach with flame atomic absorption spectroscopy is developed significantly in recent years. This review focuses on chelating resins based on Amberlite XAD resins which have been used in Flow Injection analysis since 1996.The factors like detection limit, enrichment factor and sample throughput are reported. Chelates immobilized on Amberlite XAD matrices and the metal ions separated and determined together with references are given in the review.
\end{abstract}

Keywords: Flow-Injection, FAAS, Amberlite XAD resins

\section{Introduction}

The industrial use of metals increases the metal concentrations in the air, water, and soil. These metals are widely found in the environment and will eventually enter food chain. Some heavy metals at trace concentrations are essential elements and play important roles in human metabolism. On the other hand, at higher concentrations, most of the heavy metals may be toxic. Therefore, accurate determination of trace amounts of heavy metals in the environment is very important. Flame atomic absorption spectrophotometry (FAAS) is extensively employed for quantification of metallic species and presents desirable characteristics, such as ease of operational, high selectivity, and low cost. Even though higher sensitivities are obtained by ICPOES, and ICP-MS methods, these techniques are relatively expensive and present some limitations related to the high dissolved solid contents of samples. Therefore, despite improvements in analytical detection techniques to overcome matrix interferences and to improve sensitivity and selectivity of the method, separation and/or preconcentration techniques are still required prior to determination of trace metals.

Preconcentration and speciation techniques are somewhat different from the separation techniques. In preconcentration and speciation techniques, elution or desorption procedure follows to separation procedure. Preconcentration of analytes may be defined as collection of analytes from the large volume of sample to a smaller volume of solvent. In preconcentration and speciation techniques based on SPE, one of the analytes or species have been selectively retained on a solid phase and then eluted with an appropriate eluent, and detected and quantified by an appropriate detection technique. Speciation may be defined as indicating the analytical activity of defined chemical species and measuring their distribution in a system. The preconcentration and speciation techniques have been used generally for analytical purposes in trace analysis.

There are different techniques for preconcentration such as co precipitation[1], electrode deposition, liquid-liquid extraction[2], freezing based concentration method, carbon adsorption, distillation, sublimation, evaporation, membrane filtration[3], cloud point extraction[4] and solid phase extractor (SPE) like chelating resins have been used[5]. Solid phase extraction (SPE) is one of the pre-treatment methods for the preconcentration of trace analytes from a sample. The major advantages of solid phase extraction are high selectivity and high enrichment factor that could be achieved by this technique. This method gives a higher concentration ratio of analyte than other separation methods [6]. There are several types of solid phase extractor or ion exchanger such as cation exchange resin, anion exchange resin and chelating resin. In recent years, the use of chelating resins as solid phase extractor has increased extensively for preconcentration of metal ions and it is best described in review written by A.R. Turker [7].

A variety of supports and chelating ligands have been used for the designing of chelating resins. The most prominent supports are silica gel, alumina, activated carbon, cellulose and polymers including polymeric fibers. Several chelating resins have been developed using Amberlite XAD series as support. Amberlite XAD resins $[8,9]$ have been used for the solid phase extraction of metal ions from different matrices. The use of Amberlite XAD resins with large surface area and macro porous structure convenient for preconcentration, isolation and chromatographic separation of various compounds is an improvement over activated carbon because they are more suitable for elution and are free from contamination risks. In addition XAD resins present greater adsorption capacities and easier elution than alumina, silica gel etc. However, chelating resins of high capacity are still desired and the capacity may be improved by increasing the number of chelating sites in them 
as well as the accessibility of metal ions to these sites. The chelating agent or chelators forms a chelate complex with metal ion by chelation process in which two or more separate coordinate bonds form between a polydentate ligand and a single central atom. Amberlite XAD-16 which is a base on the chemical modification of a resin surface with 4-\{[(2-hydroxyphenyl)imino]methyl $\}-1,2$-benzenediol(HIMB) is shown in Fig 1.

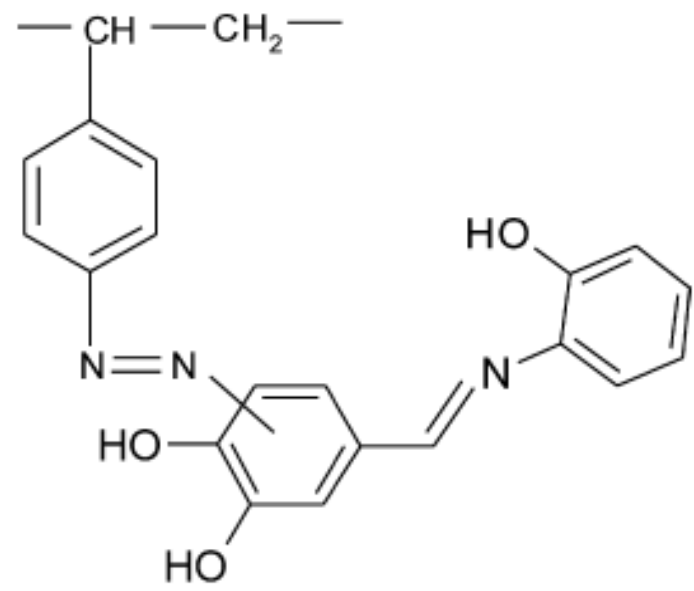

Fig.1 4-\{[(2-hydroxyphenyl)imino]methyl \}-1,2-benzenediol (HIMB)loaded Amberlite XAD-16 [Ref.10]

Extraction of metal ion using chelating resins has several advantages over conventional method:

a) High preconcentration factor and selective determination of metal ion, in which ligand possessing high selectivity to the target metal ion.

b) Lesser waste generation, since small amount of ligand and extraction solvent are used in chelating resin method, so this is an economical method and also increase the sensitivity of the system.

c) Use of less toxic solvents and thus the technique is ecofriendly in nature.

d) It is free from difficult phase separation, which is caused by the mutual solubility between water and organic solvent layer.

e) Saving of time and cost, easy regenerability of a solid phase and better sorption capacity.

f) Trace metal ions can be determined at $\mu \mathrm{gL}^{-1}$ level because the targeted ion is preconcentrated on solid phase.

An ideal analytical method for routine analysis and quality assurance should be precise and accurate, easily automated, simple and cost-effective, as well as having a high sample analysis frequency. Flow injection techniques are readily automated techniques that offer significant advantages for the determination of one selected analyte and can, therefore, be applied to routine analysis. Furthermore, flow injection (FI) offers a simpler flow manifold, reduced consumption of sample and reagents, and provides an easier, more convenient variation of the experimental parameters SPE coupled with flow injection (FI) on-line minicolumn separation and preconcentration techniques has been proved to be a good idea. This combination provides an improvement in the detection limits. The coupling of a FI system to an atomic spectroscopic detection method is well established and has various advantages, such as improvement of the action of the pneumatic nebulizer (i.e., samples with very high dissolved solids loading may be analyzed for longer periods before burner or torch blockage becomes problematic), lower consumption of samples, reduced contamination risk, and increased sample throughput [11]. The applicability of the FI-FAAS coupling is again extended by using mini-columns containing chemical materials for improving selectivity by discarding the matrix and preconcentrating the analyte, thereby improving detection limits. Most proposed analytical applications have involved the use of selective column materials or at least an enhancement of selectivity by appropriate adjustment of reaction conditions. A schematic diagram of an on-line flow injection system is shown in Figure 4.

\section{Preparation Of Chelating Resins Based On Amberlite XAD Resin}

Chelating resins have been prepared by two step synthesis:

(i) The first step involves the insertion of an appropriate functional group on the surface of polymeric support.

(ii) In second step, immobilization of ligand by virtue of coupling reaction.

The preparations of general chelating resins are given below: 
(a) Preparation of Amberlite XAD-2 immobilized with Pyrogallol

In this process nitration of Amberlite XAD-2 beads, the reduction of the nitrated resin and the subsequent diazotization of the amino resin was carried out in the preparation of pyrogallol immobilized with Amberlite XAD-2 resin. An amino-polymer was prepared by nitrating Amberlite XAD-2 with $\mathrm{HNO}_{3}$ and $\mathrm{H}_{2} \mathrm{SO}_{4}$ mixture and reducing the nitro-derivative with $\mathrm{SnCl}_{2}, 2 \mathrm{M} \mathrm{NaOH}$ and conc. $\mathrm{HCl}$. The diazotized resin was filtered, washed with ice water and allowed to react with pyrogallol at $0-3^{0} \mathrm{c}$ for $24 \mathrm{~h}$. The resulting dark brown colored beads were filtered, successively washed with $\mathrm{HNO}_{3}$, doubly distilled water and finally dried in air [9].

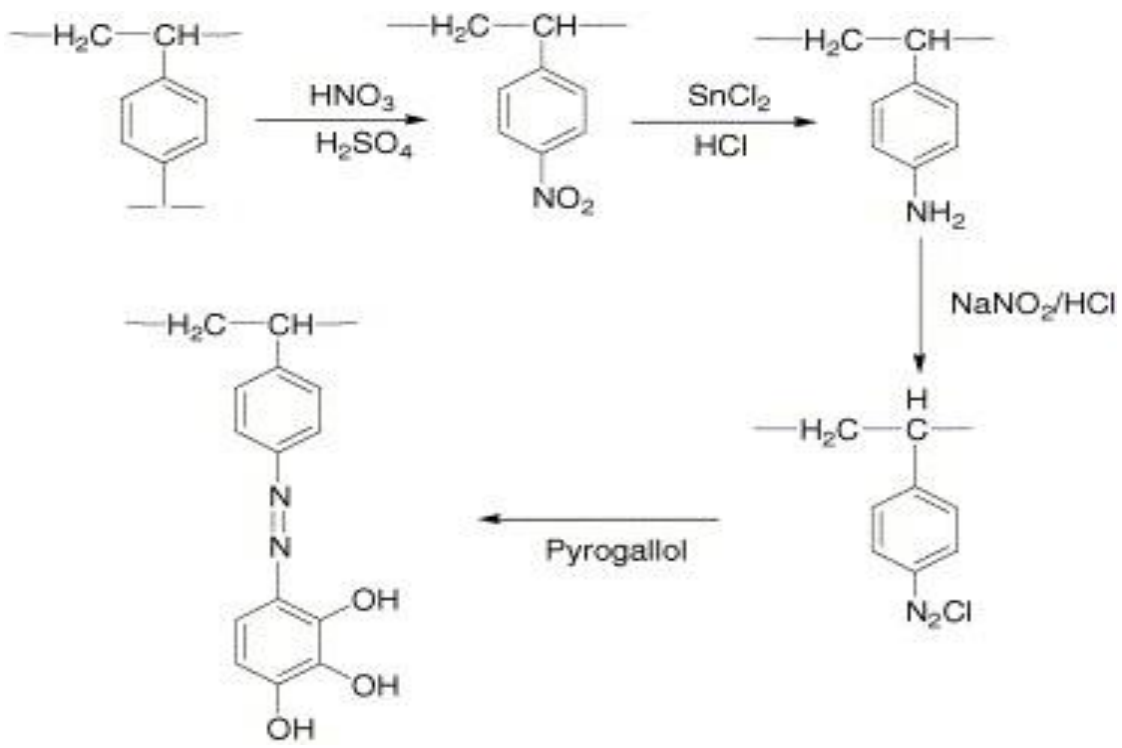

Fig.2 Synthesis of Amberlite XAD-2 immobilized with pyrogallol [Ref.12]

(b) Preparation of Amberlite XAD-2 resin functionalized with dithizone The reaction sequence for various stages of the preparation of the Amberlite XAD-2 resin functionalized with dithizone is shown in Fig. 3.

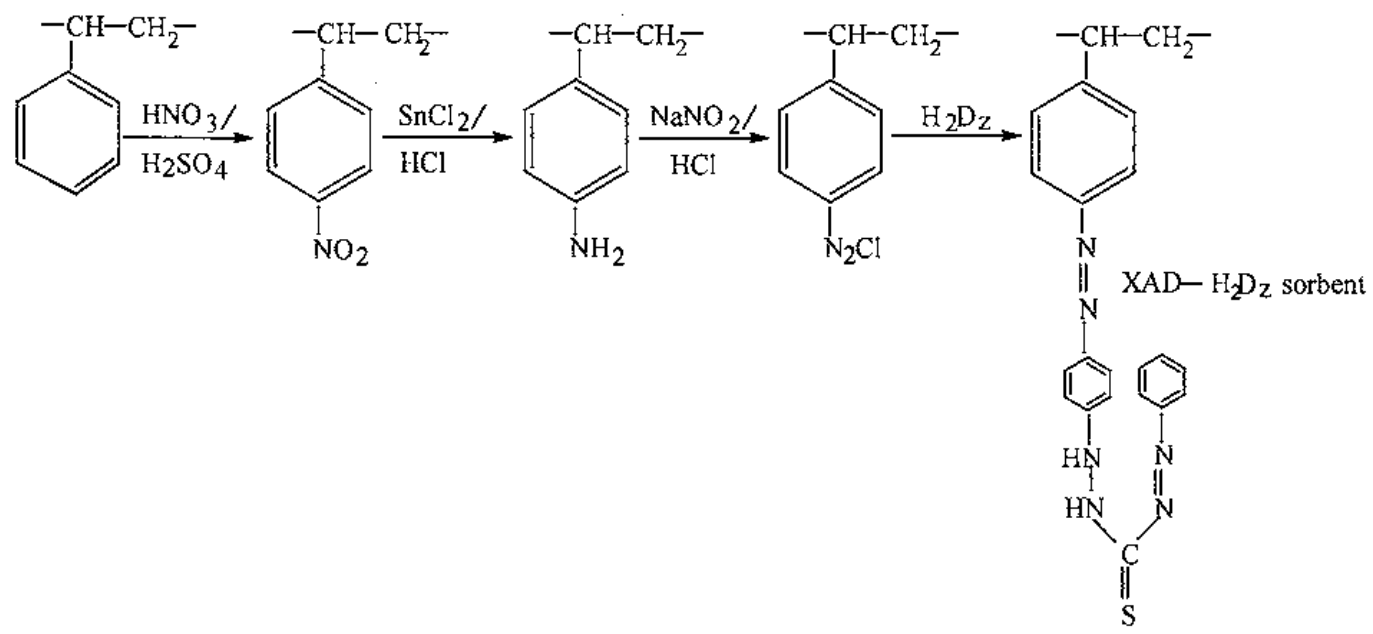

Fig.3 Synthesis of Amberlite XAD-2 resin functionalized with dithizone [Ref. 13]

\section{Preconcentration And Elution Of Metal Ions}

Preconcentration also called enrichment is a generic term for various processes employed to increase the ratio of the amount of a desired trace element to that of the original matrix and is converted into a new matrix which is suitable for the determination.

\subsection{Offline Preconcentration and elution of metal ions}

Chelating agent anchored with polymeric support through azo coupling form chelating resin. These chelating resins have various types of functional groups and form complexes with metal ions at definite $\mathrm{pH}$. 
When sample solution is passed through chelating resin at certain $\mathrm{pH}$ these resin form chelate complexes with metal ions. The reusability and separation process of resin assess by the concentration of solution and type of eluting agents $\left(\mathrm{HCl}, \mathrm{HNO}_{3} \& \mathrm{H}_{2} \mathrm{SO}_{4}\right)$. Molar concentration and flow rate such as sample flow rate, eluent flow rate are optimized and determined by atomic absorption spectrometry to obtain maximum recovery of metal ion. A comprehensive discussion about offline preconcentration using chelating resin can be found in an excellent review on "Preconcentration and Atomic Spectrometric Determination of Rare Earth Elements (REEs) in Environmental Sample" by Turker Pasinli (July, 2004) [14]. Some proposed recent analytical methods which have used the selective column material e.g. Amberlite XAD based chelating materials enhances the selectivity of different metal ions by proper adjustment of different reaction conditions in offline mode. Amberlite XAD-2 loaded resins [15-17] have low surface area as compared to Amberlite XAD-16. Modified Amberlite XAD16 resin[18-24] shows good sorption capacity and higher preconcentration factor because of large surface area and these resins can be reused for many cycles of sorption desorption without any significant change $(<2 \%)$ in its sorption capacity. However, the main problem with this technique is its low sensitivity for trace metals even at $\mathrm{mgL}^{-1}$ level, use of manual devices, more reagent consumption and time consuming.

\subsection{Online Preconcentration and Elution using the flow injection system}

On-line preconcentration systems using solid phase extraction are opportune for metal determination due to their flexibility, high sample throughput and versatility. Flow injection analysis (FIA) can be used to speed up the preconcentration process, reduce sample consumption and remove contamination from air and various vessels used for the preconcentration. Preconcentration by sorbent extraction with a flow injection system was first suggested by Ruzicka and Hansen in 1975. For this method, a chelating agent is added to the sample solution in the flow injection system. The metal chelates thus formed are preconcentrated in an appropriate column and subsequently eluted with an acid. On-line preconcentration procedure for the determination of concentration of trace metal ions in water samples uses flow-injection (FIAS-400) technique with flame atomic absorption spectrometry (FAAS) as a detection method. FIAS 400 preconcentration system comprises two peristaltic pumps, a two-positional valve and a preconcentration column as given in Fig.4 [25].

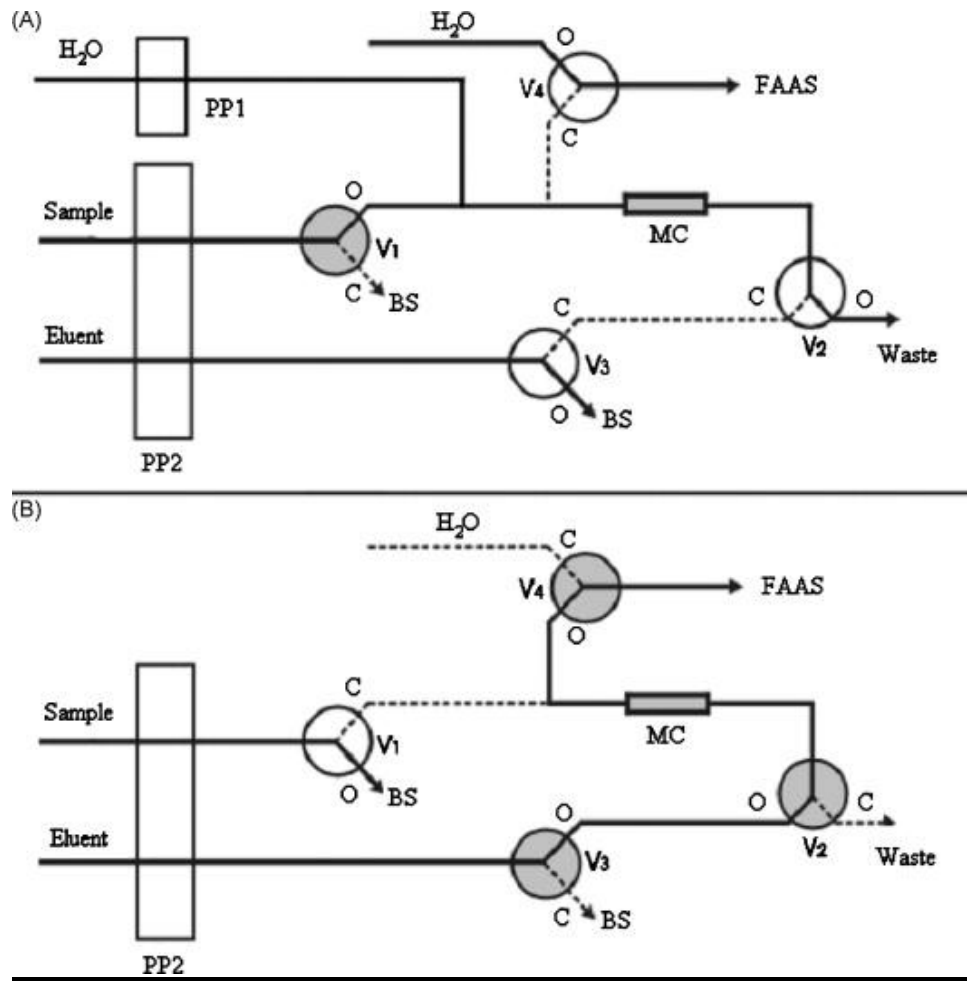

Fig.4. Diagram of the on-line preconcentration system.

(A) Adsorption step and (B) desorption step [Ref.25].

\subsubsection{Advantages of Flow Injection Analysis}

a. Major economic advantage because of their savings in labor costs.

b. Speed, which is significantly greater than that of manual devices.

c. A well-designed analyzer that can usually produce more reproducible results over a long period of time than canan operator employing a manual instrument. 
d. Economy in reagent consumption, due to a small amount of sample being used

e. High accuracy and high precision, due to the principle of flow injection analysis (FIA).

f. High rate of sampling, since FIA is also a powerful technique for separations procedures, which are often involved in a sample pretreatment stage.

g. Computer controllable system.

\subsubsection{Principles of Operation}

a. The manual handling of solutions replaced by flow injection analysis (FIA), which is computer compatible and allows automated handling of sample and reagent solutions with a strict control of reaction conditions.

b. A sample (analyte) is injected into a carrier solution which mixes through radial and convection diffusion with a reagent for a period of time (depends on the flow rate and the coil length and diameter) which flows through a micro reactor (column) into a detector or sensor of choice.

c. As the reacted plug passes through the detector, a transient signal is recorded and displayed in the form of a peak, usually within 20 seconds.

d. The height or area of the peak-shaped signal thus obtained can be used to quantify the analyte after comparison with the peaks obtained for solutions containing known concentrations of the analyte.

e. FI-FAAS set is controlled by a computer program [25] which includes: pre-filling, filling, loading and elution step. Each preconcentration cycle starts with a short loading and elution step performed to filled the tubes. Loading time is 60 s for most of the experiment. Elution includes 30 s reading time depending on the metal ion. During the sample loading step, 10 s before the valve is moved to the elution position so that signal readings are stabilized with the eluent solution. The flow rate is set in the elution step to ensure recovery of maximum metal. Absorbance peak is recorded and its height is the analytical signal.

The general procedure which is adopted in FIA-FAAS system is given below:

Synthesized chelating resin is packed in a minicolumn of the on-line preconcentration system. The minicolumn is washed with water before and after preconcentration. A sample solution containing metal ions is kept at convenient $\mathrm{pH}$ with a buffer solution and was percolated through the minicolumn that retained the cations. At this time, the remaining solution is discharged to waste. By sliding the two six-port valves (FIAS400) simultaneously, a stream of water carries the acid eluent from the loop and column, and displacing the ions. This eluate is taken direct to the nebulizer-burner system of the spectrometer and signals are measured as peak height (or maximum absorbance). Peak height is used because it resulted in precision better than peak area.

Table 1: Online Flow Injection Program for Preconcentration of Trace metal ions

\begin{tabular}{|c|c|c|c|c|c|c|}
\hline Step & Time(s) & Pump 1 & Pump 2 & Loading & Elution & Reading \\
\hline Pre-fill & 1 & + & + & + & - & - \\
\hline 1 & 10 & + & - & + & - & - \\
\hline 2 & 20 & - & + & - & + & - \\
\hline 3 & 50 & + & - & + & - & - \\
\hline 4 & 10 & + & + & + & - & - \\
\hline 5 & 30 & - & + & - & + & + \\
\hline
\end{tabular}

\section{Applications Of Chelating Resins Based On Amberlite XAD In Online Flow Injection Preconcentration System}

In an online solid phase extraction (SPE) and preconcentration method the most important aspect is the nature and properties of the sorbent materials. The chelating resins can be used in flow injection system with various detection methods like FAAS, ICP-AES, spectrophotometry, chemiluminescence and ICP-MS etc[26].There are various chelating resins have recently been used such as polyurethane foam[27-35], cellulose, silica gel[36-42], alumina[43-48], chitosan[49-51], carbon active[52] and polymeric resins like Amberlite etc. Amberlite XAD resins widely used to develop several chelating materials for preconcentration procedures due to its good physical and chemical properties such as porosity, high surface area, durability and purity.

The following review is divided into various sections describing different types of chelating resin based on Amberlite XAD and its use for the online solid phase preconcentration and determination of trace metal ions by Flame Atomic Absorption Spectroscopy (FAAS) in different samples.

These are discussed below:

\subsection{Chelating resins based on Amberlite XAD -2}

a) Amberlite XAD-2 loaded with 2-(2-thiazolylazo.-5-dimethylaminephenol) TAM

On-line preconcentration procedure for determination of trace amounts of cadmium has been proposed. It is based on chemical sorption of cadmium ions onto a minicolumn packed with Amberlite XAD-2 resin loaded with TAM reagent[54]. After being preconcentrated, cadmium was eluted by $0.50 \mathrm{~mol} \mathrm{~L}^{-1}$ hydrochloric acid 
solution and determined by on-line by flame atomic absorption spectrometry. Detection limit of $1.2 \mu \mathrm{gL}^{-1}$ for the analytical curve within the range of $0-200 \mu \mathrm{gL}^{-1}$ was obtained. An enrichment factor of 108 and a retention efficiency of $75.6 \%$ were achieved for a sample volume of $5.2 \mathrm{ml}$. The precision of the continuous preconcentration method, calculated as the relative standard deviation in sample solutions containing $10 \mu \mathrm{gL}^{-1}$ of cadmium was 4 and 9\%, regarding repeatability and reproducibility respectively. The selectivity of the proposed procedure was also evaluated. Standard reference materials were in good agreement with the certified values.

b) Amberlite XAD-2 functionalized with 3, 4-dihydroxybenzoic acid

An on-line system for preconcentration and determination of copper at $\mathrm{mgL}^{-1}$ level by flame atomic absorption spectrometry (FAAS) is proposed. Amberlite XAD-2 functionalized with 3, 4-dihydroxybenzoic acid packed in a minicolumn was used as sorbent [56]. Copper (II) ions were sorbed in the minicolumn, from which it could be eluted by hydrochloric acid solution directly to the nebulizer- burner system of the FAAS. Eluent solution was carried by water at a flow rate of $5 \mathrm{~mL} \mathrm{~min}^{-1}$. Signals were measured as peak height by using instrument software. Achieved sampling rate was 27 samples per hour. Analytical parameters were evaluated and the results demonstrated that copper can be determined, with acetate buffer to adjust the sample $\mathrm{pH}$ at 6.0, preconcentration time of $120 \mathrm{~s}$ and a sample flow rate of $6.50 \mathrm{~mL} \mathrm{~min}^{-1}$. The desorption was carried out with 30 $\mathrm{mL}$ of a $1.0 \mathrm{molL}^{-1}$ hydrochloric acid solution. An enrichment factor of 33 in $13 \mathrm{~mL}$ of sample was achieved by using the time-based technique. The detection limit (DL) was $0.27 \mu \mathrm{gL}^{-1}$. The accuracy of procedure was confirmed by copper determination in certified reference materials. Recoveries of spike additions to food samples were quantitative .These results proved also that the procedure is not affected by matrix interference and can be applied satisfactorily for copper determination in rice flour and starch samples [56].

c) Amberlite XAD-2 functionalized with $\alpha$-nitroso- $\beta$-naphthol

In this work, an on-line system for preconcentration and determination of cobalt at $\mu \mathrm{gL}^{-1}$ level is proposed [58]. Amberlite XAD-2 functionalized with $\alpha$-nitroso- $\beta$-naphthol (NN-XAD) packed in a minicolumn was used as sorbent. Cobalt (II) ions were sorbed in the minicolumn, from which it could be eluted by hydrochloric acid solution. This eluate reacted with Nitroso Salt R and the absorbance of the complex was read at $510 \mathrm{~nm}$ in a spectrophotometer. Signals were measured as peak height by using instrument software. Achieved sampling rate was 45 samples per hour Analytical parameters were evaluated. The detection limit was $6.0 \mu \mathrm{gL}^{-1}$. The proposed procedure was applied in natural waters.

d) Amberlite XAD-2 functionalized with Dithizone

A chelating resin coupling Amberlite XAD-2 functionalized with dithizone is synthesized and characterized [59]. Dissolved cadmium is field-preconcentrated using a minicolumn packed with the synthesized resin and determined by flame atomic absorption spectrometry. Five experimental variables were evaluated. The enrichment factor of 416 was obtained for $50 \mathrm{~mL}$ of sampling volume, and the detection limit $(3 \sigma)$ of the procedure was $6.7 \mathrm{ng} \mathrm{L}^{-1}$. The precision (RSD) for 11 independent determinations was $1.97 \%$. This method has been successfully applied to the determination of cadmium in natural seawater samples.

e) Amberlite XAD-2 resin anchored with pyrocatechol

A new chelating sorbent has been developed using Amberlite XAD-2 resin anchored with pyrocatechol [64]. In this on-line preconcentration system for cadmium, cobalt, copper and nickel determination metal ions were sorbed in the minicolumn, from which it could be eluted directly to the nebulizer-burner system of the flame atomic absorption spectrometer (FAAS). Elution of all metals from minicolumn can be made with 0.50 mol L ${ }^{-1} \mathrm{HCl}$ or $\mathrm{HNO}_{3}$. The enrichment factors obtained were $16(\mathrm{Cd}), 24(\mathrm{Co}), 15(\mathrm{Cu})$ and $19(\mathrm{Ni})$, for $60 \mathrm{~s}$ preconcentration time and $39(\mathrm{Cd}), 69(\mathrm{Co}), 36(\mathrm{Cu})$ and $41(\mathrm{Ni})$, if used $180 \mathrm{~s}$ preconcentration time. Under the optimum conditions, the proposed procedure allowed the determination of cadmium, cobalt, copper and nickel with detection limits of $0.31,0.32,0.39$ and $1.64 \mu \mathrm{g} \mathrm{L}^{-1}$ respectively, when used preconcentration periods of $180 \mathrm{~s}$. The accuracy of the developed procedure was sufficient and evaluated by the analysis of the certified reference materials NIST 1515 apple leaves and NIST 1570a spinach leaves. The method was applied to the analysis of food samples [64].

TABLE 2: Comparison of online flow injection method based on FAAS using Amberlite XAD -2

\begin{tabular}{|cccccccc|}
\hline Support & Chelating Agent & Analyte & Eluent & PF & DL $\left(\boldsymbol{\mu g L} \mathbf{g L}^{-1}\right)$ & Ref. \\
\hline Amberlite XAD-2 & Pyrocatechol & $\mathrm{Cd}, \mathrm{Co}$, & $\mathrm{HNO}_{3}$ & $22,23,25$ & $0.27,0.59$, & 53 \\
& 2-(2-Thiazolylazo)-5- & $\mathrm{Ni}$ & & & & 1.29 & \\
Amberlite XAD-2 & dimethylaminephenol(TAM) & $\mathrm{Cd}$ & $\mathrm{HCl}$ & 108 & 1.2 & 54 \\
Amberlite XAD-2 & 2-(20-benzothiazolylazo)-pcresol & $\mathrm{Pb}$ & $\mathrm{HCl}$ & 27 & 3.7 & 55 \\
Amberlite XAD-2 & 3,4-dihydroxybenzoic acid & $\mathrm{Cu}$ & $\mathrm{HCl}$ & 33 & 0.27 & 56 \\
Amberlite XAD-2 & \multicolumn{2}{c}{ Nitroso R salt } & $\mathrm{Co}$ & $\mathrm{HCl}$ & 79 & 1.25 & 57 \\
\hline DOI: $10.9790 / 5736-1006024454$ & www.iosrjournals.org & & & $49 \mid$ Page
\end{tabular}


Amberlite XAD-2

Amberlite XAD-2

Amberlite XAD-2

Amberlite XAD-2

Amberlite XAD-2

Amberlite XAD-2

Amberlite XAD-2

Amberlite XAD-2

Amberlite XAD- 2

Amberlite XAD-2

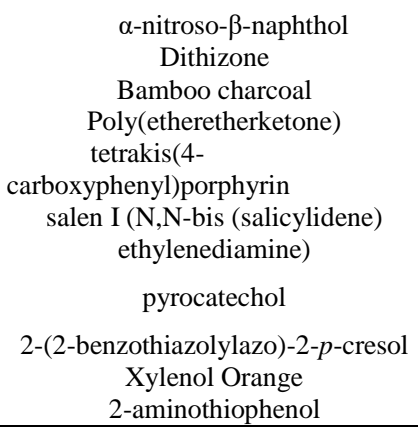

\begin{tabular}{ccccc}
$\mathrm{Co}$ & $\mathrm{HCl}$ & - & 6.0 & 58 \\
$\mathrm{Cd}$ & - & 416 & 6.7 & 59 \\
$\mathrm{Cd}$ & $\mathrm{HCl}$ & 63 & - & 60 \\
$\mathrm{~Pb}$ & - & 110 & 0.32 & 61 \\
$\mathrm{Mn}$ & - & 30 & 12 & 62 \\
$\mathrm{Cu}, \mathrm{Pb}$ & & & & \\
& $\mathrm{HNO}_{3}$ & 100,75 & $0.3,2.6$ & 63 \\
$\mathrm{Cd}, \mathrm{Co}$, & & 16,24, & $0.31,0.32$, & 64 \\
$\mathrm{Cu}, \mathrm{Ni}$ & $\mathrm{HCl}$ & 15,19 & $0.39,1.64$ & 65 \\
$\mathrm{Ni}$ & $\mathrm{HCl}$ & 30 & 1.1 & 66 \\
$\mathrm{~Pb}$ & $\mathrm{HNO}_{3}$ & 22 & 1.058 & 67 \\
$\mathrm{Cd}, \mathrm{Cu}$ & $\mathrm{HNO}_{3}$ & 28,14 & $0.14,0.54$ & 67 \\
\hline
\end{tabular}

\subsection{Chelating resins based on Amberlite XAD-4}

a) Amberlite XAD-4 impregnated with O,O-diethylditiophosphate

A method for the on-line preconcentration of Cd based on its complex formation with the ammonium salt of O,O-diethylditiophosphate (DDTP) and using the Amberlite XAD-4 resin as a solid support in a column. Cadmium was detected by flame atomic absorption spectrometry. Different conditions, such as complexing agent concentration, preconcentration time, solutions flow rates and nature and concentration of the eluent were optimized. Different detection limits could be established by using different preconcentration times, between 30 $\mathrm{s}$ and $5 \mathrm{~min}$, with corresponding DLs from 5 to $1 \mu \mathrm{gL}^{-1}$, respectively. The relative standard deviation was usually around $3 \%$, indicating a very good precision. Enriched seawaters were also analyzed, and the recoveries were between 93 and $108 \%$. The FI method is very simple and probably can be coupled to other measuring analytical techniques [68].

b) Amberlite XAD-4 impregnated with 1-(2-pyridylazo)-2-naphthol

It is an online field flow preconcentration system (FFPS) for cadmium determination in seawater. Seawater samples were collected and preconcentrated in situ by passing them with a peristaltic pump through a minicolumn packed with Amberlite XAD-4 impregnated with the complexing agent 1-(2-pyridylazo)-2naphthol. Thus, cadmium is complexed, retained, and preconcentrated without the interference of the saline matrix. Minicolumns loaded with cadmium are then returned to the laboratory where they were incorporated into a flow injection system and eluted with a small volume of an ethanolic solution of hydrochloric acid. The detection limit for $\mathrm{Cd}$ in seawater based on an enrichment factor of 1059 was $3.8 \mathrm{ng} \mathrm{L}^{-1}$. The precision (R.S.D.) obtained for different amounts of cadmium was in the range 4.1-6.5\% at the $25-100 \mathrm{ng} \mathrm{L}^{-1}$ level. Analysis of certified reference materials (SLEW-3 and NASS-5) showed good agreement with the certified value. This procedure was applied to the determination of cadmium in seawater samples [70].

c) Amberlite XAD-4 impregnate 4-(2-pyridylazo) resorcinol

In on-line flow injection analysis (FIA) system the determination of lead in water samples with a preconcentration step and spectrophotometric detection was investigated. The system is based on preconcentration of lead on a column packed with Amberlite XAD-4 resin. The developed system allowed a throughput rate of 16 samples $\mathrm{h}^{-1}$ with a 9-fold enrichment factor and detection limit of $7 \mu \mathrm{gL}^{-1} \mathrm{Dil}$. $\mathrm{HCl}$ was selected for the elution of sorbed lead ions. Recoveries of the method were in the range of 80-94\%. The procedure was validated by analysis of lead in real water samples, and the results were statistically compared with those obtained by flame atomic absorption spectrophotometry (FAAS). The results obtained both by the proposed method and by FAAS were in good agreement [76].

TABLE 3: Comparison of online flow injection method based on FAAS using Amberlite XAD-4

\begin{tabular}{|c|c|c|c|c|c|c|}
\hline Support & Chelating Agent & Analyte & Eluent & PF & $\mathrm{DL}\left(\mu \mathrm{gL}^{-1}\right)$ & Ref. \\
\hline Amberlite XAD- 4 & O,O-diethyldithiophosphate & $\mathrm{Cd}$ & $\mathrm{HNO}_{3}$ & - & 5 & 68 \\
\hline Amberlite XAD-4 & 1-(2-pyridylazo)-2-naphthol & $\begin{array}{c}\mathrm{Cd}, \mathrm{Zn}, \\
\mathrm{Co}, \mathrm{Cu}, \\
\mathrm{Ni}, \mathrm{Mn}, \mathrm{Pb}\end{array}$ & $\mathrm{H}_{2} \mathrm{SO}_{4}$ & - & 10 & 69 \\
\hline Amberlite XAD-4 & 1-(2-pyridylazo)-2-naphthol & $\mathrm{Cd}$ & $\mathrm{HCl}$ & 1059 & 3.8 & 70 \\
\hline Amberlite XAD-4 & 3,4-dihydroxybenzoic acid & $\begin{array}{l}\mathrm{Cu}, \mathrm{Fe}, \mathrm{Ni}, \\
\mathrm{Zn}\end{array}$ & $\mathrm{HCl}$ & $22,15,12,54$ & $\begin{array}{l}2.3,5.0 \\
7.8,0.1\end{array}$ & 71 \\
\hline Amberlite XAD-4 & $\beta$-nitroso- $\alpha$-naphthol & $\mathrm{Cu}$ & - & 61 & 0.4 & 72 \\
\hline Amberlite XAD-4 & 2-aminothiophenol & $\mathrm{Cd}, \mathrm{Ni}$ & $\mathrm{HCl}$ & 99,43 & $0.3,0.8$ & 73 \\
\hline Amberlite XAD-4 & $\begin{array}{l}\text { 2,6-dihydroxyphenyl- } \\
\text { diazoaminoazobenzene }\end{array}$ & $\begin{array}{l}\mathrm{Cd}, \mathrm{Co}, \\
\mathrm{Cu}, \mathrm{Zn}\end{array}$ & $\mathrm{HCl}$ & $\begin{array}{l}42,33 \\
28,31\end{array}$ & $\begin{array}{l}0.1,0.5 \\
0.3,0.2\end{array}$ & 74 \\
\hline Amberlite XAD-4 & 4-(2-pyridylazo) resorcinol & $\mathrm{Cu}$ & $\mathrm{HCl}$ & - & - & 75 \\
\hline Amberlite XAD-4 & 4-(2-pyridylazo) resorcinol & $\mathrm{Pb}$ & $\mathrm{HCl}$ & 9 & 7 & 76 \\
\hline Amberlite XAD-4 & $\begin{array}{l}\text { 4-phenylthiosemicarbazide, } 2,3 \\
\text { dihydroxybenzaldehyde and 2- } \\
\text { thiophenecarboxaldehyde }\end{array}$ & $\begin{array}{c}\mathrm{Cd}, \mathrm{Co}, \\
\mathrm{Cu}, \mathrm{Ni} \mathrm{Pb}\end{array}$ & $\mathrm{HNO}_{3}$ & - & - & 77 \\
\hline
\end{tabular}




\subsection{Chelating resins based on Amberlite XAD-7, XAD-8 and XAD-16}

a) Amberlite XAD-7 loaded with 4-(n-octyl)diethylenetriamine

In this system, as online preconcentration procedure for determination of $\mathrm{Rh}, \mathrm{Pd}$ and Pt by FIA-FAAS method. Quantitative recovery of rhodium and platinum in the form of their hexachloride complexes was achieved under non-equilibrium conditions of on-line dilution. Metals recovered are quantitatively eluted with hydrochloric acid solution in ethanol. The RSD values are $0.03-0.08$ at 50-ppb concentration level. The detection limits are 3-8 ppb for $1 \mathrm{~min}$ of preconcentration. The accuracy of the procedure was verified by the analysis of by the analysis of standard reference materials of sulfide ores and alloys [78].

b) Amberlite XAD-8 functionalized with diethyldithiocarbamate

A flow-injection, solid-phase extraction, preconcentration method was developed for the determination of lead in soil and water samples by flame atomic absorption spectrometry. Lead, in the form of the diethyldithiocarbamate complex, was retained on a miniature column. The complex retained from $\mathrm{pH} 9.0$. Afterwards, lead was eluted with ethanol. The detection limit was $2 \mu \mathrm{gL}^{-1}$ for preconcentration at $2.2 \mathrm{~mL} \mathrm{~min}^{-1}$ for $120 \mathrm{~s}$. The relative standard deviation (R.S.D) was less than $4 \%$ for concentrations down to $400 \mu \mathrm{gL}^{-1}$. The procedure was validated by the analysis of NIST standard reference material which contains lead at a concentration of $1162 \mu \mathrm{gL}^{-1}$. Recoveries of spike additions to artificial sea water and tap water were quantitative [79].

c) Amberlite XAD-16 functionalized on salicylanilide

Salicylanilide has been incorporated into Amberlite XAD-16 through an azo spacer[79].The optimum $\mathrm{pH}$ values for the maximum sorption of analyte were 9.0 for $\mathrm{Cu}(\mathrm{II}), \mathrm{Co}(\mathrm{II}), \mathrm{Ni}(\mathrm{II}), \mathrm{Zn}(\mathrm{II}), \mathrm{Cr}(\mathrm{III})$, and 6.0 for $\mathrm{Cd}(\mathrm{II})$ and $\mathrm{Pb}(\mathrm{II})$, respectively, with the half-loading time, $\mathrm{t}_{1 / 2}$ ranging from 3.5 to $11.0 \mathrm{~min}$. The breakthrough capacities for $\mathrm{Cu}(\mathrm{II}), \mathrm{Co}(\mathrm{II}), \mathrm{Ni}(\mathrm{II}), \mathrm{Zn}(\mathrm{II}), \mathrm{Cr}(\mathrm{III}), \mathrm{Cd}(\mathrm{II})$, and $\mathrm{Pb}$ (II) were found to be 697.91, 641.83, 629.32, $551.38,531.72,249.11$ and $125.36 \mu \mathrm{moL} \mathrm{g}^{-1}$ respectively with corresponding preconcentration factors of 440 , $380,380,360,280,280$ and 260 . The detection limits were found to be $0.56,0.64,0.65,0.70,0.75,0.88$ and $1.17 \mu \mathrm{gL}^{-1}$ respectively. Analysis of standard reference materials and recovery experiments were carried out for the validation of the method. Practical utility has been demonstrated by successfully determining metal ions in natural water, mango pulp, leafy vegetables and fish [80].

\section{d) Amberlite XAD-16 functionalized with 4-(2-Thiazolylazo)-resorcinol (TAR)}

An on-line chromium preconcentration and determination system implemented with flame atomic absorption spectrometry (FAAS) associated to flow injection (FI) was studied by Gustavo M. Wuilloud and others [80]. For the retention of chromium, on 4-(2-Thiazolylazo)-resorcinol (TAR) immobilized Amberlite XAD-16 was used, at pH 5.0. The Cr- TAR complex was removed from the minicolumn with ethanol, an enrichment factor of 50 was obtained for the preconcentration of $50 \mathrm{ml}$ of sample solution. The detection limit value for the preconcentration of $50 \mathrm{ml}$ of aqueous solution of chromium was $20 \mathrm{ngL}^{-1}$ and relative standard deviation (RSD) was $2.9 \%$, calculated from the peak heights obtained. The calibration graph using the preconcentration system for chromium was linear with a correlation coefficient of 0.9997 at levels near the detection limits up to at least $100 \mu \mathrm{gL} \mathrm{L}^{-1}$. The method was successfully applied to the determination of chromium in sample solutions [81].

TABLE 4: Comparison of online flow injection method based on FAAS using Amberlite XAD-7, XAD-8 and XAD- 16

\begin{tabular}{|c|c|c|c|c|c|c|}
\hline Support & Chelating Agent & Analyte & Eluent & $\mathbf{P F}$ & $\mathrm{DL}\left(\mu \mathrm{gL}^{-1}\right)$ & Ref. \\
\hline Amberlite XAD-7 & 4-(n-octyl)diethylenetriamine & $\mathrm{Rh}, \mathrm{Pd}, \mathrm{Pt}$ & $\mathrm{HCl}$ & 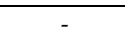 & $3-8$ & 78 \\
\hline Amberlite XAD-8 & diethyldithiocarbamate & $\mathrm{Pb}$ & ethanol & - & 2 & 79 \\
\hline Amberlite XAD-16 & Salicylanilide & $\begin{array}{c}\mathrm{Cu}, \mathrm{Co} \\
\text {,Ni,Zn, } \\
\mathrm{Cr}, \mathrm{Cd} \\
\text {,Pb }\end{array}$ & $\mathrm{HCl}$ & $\begin{array}{c}440,380, \\
350,360 \\
280,280 \\
260\end{array}$ & $\begin{array}{c}0.56,0.64 \\
0.65,0.70 \\
0.75,0.88 \\
1.17\end{array}$ & 80 \\
\hline Amberlite XAD-16 & $\begin{array}{c}\text { 4-(2-Thiazolylazo)- } \\
\text { resorcinol (TAR) }\end{array}$ & $\mathrm{Cr}$ & - & 50 & 20 & 81 \\
\hline Amberlite XAD-16 & 1-(2-pyridylazo) 2-naphtol & $\mathrm{Cd}$ & $\mathrm{HNO}_{3}$ & - & 1.5 & 82 \\
\hline
\end{tabular}

\section{Conclusion}

At trace level the analysis of metal ions is one of the most difficult and complicated analytical tasks since it requires the rigorous requirements of versatility, specificity, accuracy, and sensitivity. The direct determination with various instrumental methods is not possible owing to matrix effect and low concentration of metal ions in the sample. Thus the need of separation and preconcentration of metal ions arises to enhance the concentration of the solution to be determined. Selective determination of metal ions will be possible by using a 
chelating resin having a ligand possessing high selectivity to the targeted metal ion. Solid phase extraction is very popular technique currently available for rapid and selective sample preparation. The online preconcentration and determination by FAAS improved significantly the performance of the off-line FAAS method. Combination of flow injection systems with FAAS using polymeric resins functionalized with complexing agent can be a promising way in preconcentration and determination of cations in a wide range of samples. In this review different chelating solid phase materials used in on-line flow injection systems with FAAS as detection method have been evaluated with specific information in reference to limits of detection, preconcentration factors sample throughput.

\section{Refrences}

[1] A. Efendioglu, M. Yagan, B. Bat; Bi(III)4-methylpiperidinedithiocarbamate coprecipitation procedure for separation-preconcentration of trace metal ions in water samples by flame atomic absorption spectrometric determination; J.Hazard. Mater. 149 (2007) 160-165.

[2] M.R. Jamali, Y. Assadi, R.R. Kozani, F. Shemirani; Homogeneous Liquid-Liquid Extraction Method For Selective Separation And Preconcentration Of Trace Amounts Of Palladium; E-Journal Of Chemistry 6(4) (2009) 1077-1084.

[3] M. Soylak, Y.E. Unsal, N. Kizil, A. Aydin; Utilization of membrane filtration for preconcentration and determination of Cu(II) and $\mathrm{Pb}(\mathrm{II})$ in food, water and geological samples by atomic absorption Spectrometry; Food and Chemical Toxicology 48 (2010) 517521.

[4] M. Ghaedi, K. Niknam, E. Niknam, M. Soylak; Application Of Cloud Point Extraction For Copper, Nickel, Zinc And Iron Ions In Environmental Samples; J. of the Chinese Chemical Society 56 (2009) 981-986.

[5] B.S. Garg, R.K. Sharma, N. Bhojak, S. Mittal; Chelating Resins and their Application in the Analysis of Trace Metal Ions; Microchem. J. 61(1999) 94-114

[6] A. Zwir-Ferenc, M. Biziuk; Solid Phase Extraction Technique - Trends, Opportunities and Applications; Polish J. of Environ. Stud. 15(5) (2006) 677-690.

[7] A. R. Türker; Separation, Preconcentration And Speciation Of Metal Ions By Solid Phase Extraction; Sep. \& Purification Reviews 41(2012) 169-206.

[8] M. Kumar, D. P. S. Rathore, A. K. Singh; Pyrogallol Immobilized Amberlite XAD-2: A Newly Designed Collector for Enrichment of Metal Ions Prior to their Determination by Flame Atomic Absorption Spectrometry; Microchim. Acta 137 (2001) 127-134.

[9] K. Chalapathi, L.R. babu, P. Madhu, G.P. Maddaiah; 2-Mercaptobenzimidazole Immobilized with Amberlite Xad-2 Using as Solid Phase Extractor for the Determination of $\mathrm{Fe}(\mathrm{II}), \mathrm{Cu}(\mathrm{II})$, and $\mathrm{Cd}(\mathrm{II})$ in Sewage and Waste Water Samples by Flame Atomic Absorption Spectrometry 1 (2) (2010) 27-35.

[10] G. Venkatesh, A.K. Singh; 4-\{[(2-Hydroxyphenyl)imino]methyl $\}$-1,2-benzenediol (HIMB) anchored Amberlite XAD-16: Preparation and applications as metal extractants; Talanta 71 (2007) 282-287.

[11] D. Kara, A. Fisherb, S.J. Hill; Preconcentration and determination of trace elements with 2,6-diacetylpyridine functionalized Amberlite XAD-4 by flow injection and atomic spectroscopy; Analyst 130 (2005) 1518-1523.

[12] T.P. Rao, P. Metilda, J.M. Gladis; Preconcentration techniques for uranium(VI) and thorium(IV) prior to analytical determinationan overview; Talanta 68 (2006) 1047-1064.

[13] W.U. Dongmei, A. WANG, and L. GUO; Synthesis and Application of Amberlite XAD-2 Functionalized with Dithizone for Field Preconcentration and Separation of Trace Cadmium in Seawater; Anal. Sci. 22 (2006) 1245-1248.

[14] T. Pasinli; Preconcentration and Atomic Spectrometric Determination of Rare Earth Elements (REEs) in Environmental Samples (2004).

[15] R. Saxena, A.K. Singh; Pyrocatechol Violet immobilized Amberlite XAD-2: synthesis and metal-ion uptake properties suitable for analytical applications; Anal. Chim. Acta 340 (1997) 285-290.

[16] M. Kumar, D.P.S. Rathore, A.K. Singh; Amberlite XAD-2 functionalized with o-aminophenol:synthesis and applications as extractant for copper(II), cobalt(II), cadmium(II), nickel(II), zinc(II) and lead(II); Talanta 51 (2000) 1187-1196.

[17] R. Saxena, A.K. Singh, D. P. S. Rathore; Salicylic acid functionalize polystyrene sorbent amberlite XAD-2. Synthesis and applications as a preconcentrator in the determination of zinc(II) and lead(II) by using atomic absorption spectrometry; Analyst 120 (1995) 403-405.

[18] G. Venkatesh, A.K. Singh; 4-\{[(2-Hydroxyphenyl)imino]methyl $\}$-1,2-benzenediol (HIMB) anchored Amberlite XAD-16: Preparation and applications as metal extractants; Talanta 71 (2007) 282-287.

[19] R.K. Sharma, P. Pant; Preconcentration and determination of trace metal ions from aqueous samples by newly developed gallic acid modified Amberlite XAD-16 chelating resin; J.Hazard. Mater. 163 (2009) 295-301.

[20] M. Ghaedi, B. Karami, Sh. Ehsani, F. Marahel, M. Soylak; Preconcentration-separation of $\mathrm{Co}^{2+}, \mathrm{Ni}^{2+}, \mathrm{Cu}^{2+}$ and $\mathrm{Cd}^{2+}$ in real samples by solid phase extraction of a calix[4] resorcinarene modified Amberlite XAD-16 resin; J. Hazard. Mater. 172 (2009) 802808 .

[21] M. Ghaedi, K. Niknam, K. Taheri, H. Hossainian, M. Soylak; Flame atomic absorption spectrometric determination of copper, zinc and manganese after solid-phase extraction using 2,6-dichlorophenyl-3,3-bis(indolyl)methane loaded on Amberlite XAD-16; Food and Chemical Toxicology 48 (2010) 891-897.

[22] M. Merdivan, M. Zahir Du, C. Hamamci; Sorption behaviour of uranium(VI) with N,N-dibutyl-N-benzoylthiourea Impregnated in Amberlite XAD-16; Talanta 55 (2001) 639-645.

[23] G. Venkatesh, A.K. Singh; 2-\{[1-(3,4-Dihydroxyphenyl) methylidene] amino\}benzoic acid immobilized Amberlite XAD-16 as metal extractant; Talanta 67 (2005) 187-194

[24] A. Tunceli, A.R. Turker; Speciation of $\mathrm{Cr}(\mathrm{III})$ and $\mathrm{Cr}(\mathrm{VI})$ in water after preconcentration of its 1,5-diphenylcarbazone complex on amberlite XAD-16 resin and determination by FAAS; Talanta 57 (2002) 1199-1204.

[25] E. Martendal, H.F. Maltez, E. Carasek; Speciation of $\mathrm{Cr}$ (III) and $\mathrm{Cr}(\mathrm{VI})$ in environmental samples determined by selective separation and preconcentration on silica gel chemically modified with niobium(V) oxide; J. of Hazard. Mat. 161(2009) 450-456.

[26] D. Kara; The Use of Chelating Solid Phase Materials in Flow Injection Systems: A Review; Anal. Lett. 44(2011) 457-482.

[27] W.N.L. Dos Santos, J.L.O. Costa, R.G.O. Araujo, D.J. de Jesus, A.C.S. Costa; An on-line pre-concentration system for determination of cadmium in drinking water using FAAS; J.Hazard. Mater. 137 (2006) 1357-1361. 
[28] V.A. Lemos, R.E. Santelli, M.S. Carvalho, S.L.C. Ferreira; Application of polyurethane foam loaded with BTAC in an on-line preconcentration system: cadmium determination by FAAS; Spectrochim. Acta 55 (2000) 1497-1502.

[29] A.N. Anthemidis, G.A. Zachariadis, J.A. Stratis; On-line preconcentration and determination of copper, lead and chromium(VI) using unloaded polyurethane foam packed column by flame atomic absorption spectrometry in natural waters and biological samples; Talanta 58 (2002) 831-840.

[30] A. Moghimi, N. Tajodini; Preconcentration of Copper(II) in Water Samples Using Polyurethane Foam/2-(6'-Ethyl-2'benzothiazolylazo)chromotropic Acid; Asian J. of Chem. 22 (2010) 3325-3334.

[31] W.N.L. dos Santos, C.M.M. dos Santos, J.L.O. Costa, H.M.C. Andrade, S.L.C. Ferreira; Multivariate optimization and validation studies in on-line pre-concentration system for lead determination in drinking water and saline waste from oil refinery; Microchem. J. 77 (2004) 123-129.

[32] E. M. Gama, A.D.S. Lima, V.A. Lemos; Preconcentration system for cadmium and lead determination in environmental samples using polyurethane foam/Me-BTANC; J. Hazard. Mater. 136 (2006) 757-762.

[33] R.J. Cassella, V.A. Salim, L.S. Jesuíno, R.E. Santelli, S.L.C. Ferreira, M.S. De Carvalho; Flow injection determination of cobalt after its sorption onto polyurethane foam loaded with 2-(2-thiazolylazo)-p-cresol (TAC); Talanta 54 (2001) 61-67.

[34] V.A. Lemos, W.N.L. dos Santos, J.S. Santos, M.B. de Carvalho; On-line preconcentration system using a minicolumn of polyurethane foam loaded with Me-BTABr for zinc determination by Flame Atomic Absorption Spectrometry; Anal. Chim. Acta 481 (2003) 283-290.

[35] S.L.C. Ferreira, W.N.L. dos Santos, M.A. Bezerra, V.A. Lemos, J.M. Bosque-Sendra; Use of factorial design and Doehlert matrix for multivariate optimization of an on-line preconcentration system for lead determination by flame atomic absorption spectrometry; Anal. Bioanal. Chem. 375 (2003) 443-449.

[36] H. Franc, Maltez, M.A. Vieira, A. S. Ribeiro, A. J. Curtius, E. Carasek; Simultaneous on-line pre-concentration and determination of trace metals in environmental samples by flow injection combined with inductively coupled plasma mass spectrometry using silica gel modified with niobium(V) oxide; Talanta 74 (2008) 586-592.

[37] P.Liu, Z. Su, X. Wu, Q. Pu; Application of isodiphenylthiourea immobilized silica gel to flow injection on-line microcolumn preconcentration and separation coupled with flame atomic absorption spectrometry for interference-free determination of trace silver, gold, palladium and platinum in geological and metallurgical samples; J. Anal Spectrom. 17(2002) $125-130$.

[38] H. Franc Maltez, E. Carasek; Chromium speciation and preconcentration using zirconium(IV) and zirconium(IV) phosphate chemically immobilized onto silica gel surface using a flow system and FAAS[J]; Talanta 65 (2005) 537-542.

[39] Yan XP, Sperling M, Welz B; Application of a macrocycle immobilized silica gel sorbent to flow injection on-line microcolumn preconcentration and separation coupled with flame atomic absorption spectrometry for interference-free determination of trace lead in biological and environmental samples; Anal. Chem.19 (1999)4216-22.

[40] P. Liu, Q. Pu, Z. Su; Synthesis of silica gel immobilized thiourea and its application to the on-line preconcentration and separation of silver, gold and palladium; Analyst 125 (2000) 147-150.

[41] E.L. Silva, E.M. Ganzarolli, E. Carasek; Use of Nb2O5-SiO2 in an automated on-line preconcentration system for determination of copper and cadmium by FAAS; Talanta 62 (2004) 727-733

[42] G.G. Bortoleto, G.T. Macarovscha, S. Cadore; Determination of cadmium by flame atomic absorption spectrometry after preconcentration on silica gel modified with cupferron; J. Braz. Chem. Soc. 15 (2004) 313-317.

[43] F. Shakerian, S. Dadfarnia, A.M.H. Shabani, M. Rohani; Multi Simplex optimization of on-line sorbent proconcentration and determination of iron by FI-AAS and microcolumn of immobilized ferron; Talanta 77 (2008) 551-555.

[44] A.M. H. Shabani, S. Dadfarnia, K. Dehghan; On-line preconcentration and determination of cobalt by chelating microcolumns and flow injection atomic spectrometry; Talanta 59 (2003) 719-725.

[45] S. Dadfarnia, A.M.H. Shabani, F. Tamaddon, M. Rezaei; Immobilized salen (N,N'-bis (salicylidene) ethylenediamine) as a complexing agent for on-line sorbent extraction/preconcentration and flow injection-flame atomic absorption spectrometry; Anal. Chim. Acta 539 (2005) 69-75.

[46] A.M.H. Shabani, S. Dadfarnia, T. Moosavinejad, S.H. Ahmadi; On-line preconcentration system using a microcolumn packed with Alizarin Red S-modified alumina for zinc determination by flame atomic absorption Quim; Nova 32(2009)1202-1205.

[47] S. R. Amais, S. J. Ribeiro, G.M. Segatelli, V.P. I. Yoshida, O.P. Luccas, C.R.T. Tarley; Assessment of nanocomposite alumina supported on multi-wall carbon nanotubes as sorbent for on-line nickel preconcentration in water samples; Sep. and Purification Technology 58 (2007)122-128

[48] S. Dadfarnia, M. H. Jafarzadeh; Online Trace Enrichment and Determination of Cobalt Ion as an Anionic Complex by Flow Injection Atomic Absorption Spectrometry; Microchem. J. 63 (1999) 226-234.

[49] A.O. Martins, E.L.D. Silva, E. Carasek, Mauro, C.M Laranjeira, V.T.deFávere; Sulphoxine immobilized onto chitosan microspheres by spray drying: application for metal ions preconcentration by flow injection analysis; Talanta 63 (2004) $397-403$.

[50] A.O. Martins, E. L.D. Silva, E. Carasek, N.S. Gonçalves, M.C. M. Laranjeira, V. T. de Favere; Chelating resin from functionalization of chitosan with complexing agent 8-hydroxyquinoline: application for metal ions on line preconcentration system; Anal Chim. Acta 521(2004) 157-162.

[51] J. S. Carletto, K. Cravo, Di P. Roux, H. F. Maltez, E. Martendal, E. Carasek; Use of 8-hydroxyquinoline-chitosan chelating resin in an automated on-line preconcentration system for determination of zinc(II) by FAAS; J. Hazard. Mater. 157 (2008) 88-93.

[52] A.A. Ensafi, R.A. Ghaderi; On-line solid phase selective separation and preconcentration of Cd(II) by solid-phase extraction using carbon active modified with methyl thymol blue; J. Hazard. Mater. 148 (2007) 319-325.

[53] V.A. Lemos, E.M. Gama, A.D.S. Lima; On-Line Preconcentration and Determination of Cadmium, Cobalt and Nickel in Food Samples by Flame Atomic Absorption Spectrometry Using a New Functionalized Resin; Microchim. Acta. 153(2006) 179-186.

[54] M. H.A. Meloa, S. L.C. Ferreiraa, U.Ricardo, E. Santelli; Determination of cadmium by FAAS after on-line enrichment using a mini column packed with AmberliteXAD-2 loaded with TAM; Microchem. J. 65 (2000) 59-65.

[55] S.L.C. Ferreiraa, U.V.A. Lemos, R.E. Santelli, E. Ganzarolli, A.J. Curtius; An automated on-line flow system for the preconcentration and determination of lead by flame atomic absorption spectrometry; Microchem. J. 68 (2001) 41-46.

[56] V. A. Lemos, P. Xavier Baliza, R.T. Yamaki, M.E. Rocha, A.P.O. Alves; Synthesis and application of a functionalized resin in online system for copper preconcentration and determination in foods by flame atomic absorption spectrometry; Talanta 61 (2003) 675-682

[57] V.A. Lemos, J.S. Santos, L.S. Nunes, M.B. de Carvalho, P.X. Baliza, R.T. Yamaki; Amberlite XAD-2 functionalized with Nitroso R salt: synthesis and application in an online system for preconcentration of cobalt; Anal. Chim. Acta 494 (2003) 87-95

[58] V.A. Lemos, J.S. Santos, P.X. Baliza; Synthesis of a-Nitroso-b-Naphthol Modified Amberlite XAD-2 Resin and its Application in On-Line Solid Phase Extraction System for Cobalt Preconcentration; Sep. Sci. and Tech. 39 (2004) 3317-3330. 
[59] D. Wu, A. Wang, L. GUO; Synthesis and Application of Amberlite XAD-2 Functionalized with Dithizone for Field Preconcentration and Separation of Trace Cadmium in Seawater; Anal. Sci. 22 (2006) 1245-1248.

[60] S.Zha, H.Liang, H.Y. Zhengzhong, Y. Suqing, C.X. Zhu, M. Cheng; Online Preconcentration and Determination of Trace Levels Cadmiumin Water Samples Using Flow Injection Systems Coupled with Flame AAS; Clean 38 (2010) 146 - 152.

[61] A.N. Anthemidis, I.S.I. Adam, G.A. Zachariadis; Poly(etheretherketone)-turnings a novel sorbent material for lead determination by flow injection flame atomic absorption spectrometry and factorial design optimization; Talanta 81 (2010) 996-1002.

[62] M. Knap, K. Kilian, K. Pyrzynska; On-line enrichment system for manganese determination in water samples using FAAS; Talanta 71 (2007) 406-410.

[63] S. Dadfarnia, A.M.H. Shabani, F. Tamaddon, M. Rezaei; Immobilized salen (N, N-bis (salicylidene) ethylenediamine) as a complexing agent for on-line sorbent extraction/preconcentration and flow injection-flame atomic absorption spectrometry; Anal. Chim. Acta 539 (2005) 69-75.

[64] V.A. Lemos, D.G. da Silva, A. L. de Carvalho, D.D.A. Santana, Geisiane dos Santos Novaes, Adenilde Souza dos Passos; Synthesis of amberlite XAD-2-PC resin for preconcentration and determination of trace elements in food samples by flame atomic absorption spectrometry; Microchem. J. 84 (2006) 14-21.

[65] S. L.C. Ferreira, W.N.L. dos Santos, V.A. Lemos; On-line preconcentration system for nickel determination in food samples by flame atomic absorption spectrometry; Anal. Chim. Acta 445 (2001) 145-151.

[66] R. Saxena, S. Saxena, P. Sarojam; Detemination of lead in water using Amberlite XAD-2 functionalized with Xylenol Orange Resin as Column Material for On-Line Flow Injection- Flame Atomic Absoption Spectrosmetry Analysis; Atomic Spectrosc. 33(2012) 8391.

[67] V.A. Lemos, P.X. Baliza; Amberlite XAD-2 functionalized with 2-aminothiophenol as a new sorbent for on-line preconcentration of cadmium and copper; Talanta 67 (2005) 564-570.

[68] E.J. dos Santos, A.B. Herrmann, A.S. Ribeiro, A.J. Curtius; Determination of Cd in biological samples by flame AAS following online preconcentration by complexation with O,O-diethyldithiophosphate and solid phase extraction with Amberlite XAD-4; Talanta 65 (2005) 593-597.

[69] A. Islam, M.A. Laskar, A. Ahmad; The efficiency of Amberlite XAD-4 resin loaded with 1-(2-pyridylazo)-2-naphthol in preconcentration and separation of some toxic metal ions by flame atomic absorption spectrometry; Environ. Monit. Assess175 (2011) 201-212

[70] M.C. Yebra, A. Garcia, N. Carro, A. Moreno-Cid, L. Puig; Design of a field flow preconcentration system for cadmium determination in seawater by flow-injection-atomic absorption spectrometry; Talanta 56 (2002) 777-785.

[71] L.S.G. Teixeira, M.D.A. Bezerra,V.A. Lemos, H.C.D. Santos, D.S. de Jesus, A.C.S. Costa; Determination of Copper, Iron, Nickel, and Zinc in Ethanol Fuel by Flame Atomic Absorption Spectrometry Using On-Line Preconcentration System; Sep. Sci. and Tech., 40 (2005) 2555-2565

[72] V.A. Lemos, E.S. Santos, E.M. Gama; A comparative study of two sorbents for copper in a flow injection preconcentration system; Sep. and Purification Tech. 56 (2007) 212-219.

[73] V.A. Lemos, C.G. Novaes, A.D.S. Lima, D.R. Vieira; Flow injection preconcentration system using a new functionalized resin for determination of cadmium and nickel in tobacco samples; J. Hazard. Mater. 155 (2008) 128-134.

[74] Y. Liu, Y. Guo, S. Meng, X. Chang; Online separation and preconcentration of trace heavy metals with 2,6-dihydroxyphenyldiazoaminoazobenzene impregnated Amberlite XAD-4; Microchim. Acta 158 (2007) 239-245.

[75] M.C. Yebra, N. Carro, A. Moreno-Cid; Optimization of a field flow pre-concentration system by experimental design for the determination of copper in sea water by flow-injection-atomic absorption spectrometry; Spectrochim. Acta 57 (2002) 85-93.

[76] J. Klamtet, N. Suphrom, C. Wanwat; A flow injection system for the spectrophotometric determination of lead after preconcentration by solid phase extraction onto Amberlite XAD-4; Mj. Int. J. Sci. Tech. 2 (2008) 408-417.

[77] D. Karaa, A. Fisher, S.J. Hill; Determination of trace heavy metals in soil and sediments by atomic spectrometry following preconcentration with Schiff bases on Amberlite XAD-4; J. Hazard. Mater. 165 (2009) 1165-1169.

[78] I.A. Kovalev, L.V. Bogacheva, G.I. Tsysin, A.A. Formanovsky, Yu. A. Zolotov; FIA-FAAS system including on-line solid phase extraction for the determination of palladium, platinum and rhodium in alloys and ores; Talanta 52 (2000) 39-50.

[79] L. Elci, U, Z. Arslan, J.F. Tyson; Flow injection solid phase extraction with Chromosorb 102: determination of lead in soil and waters by flame atomic absorption spectrometry; Spectrochim. Acta 55 (2000) 1109-1116.

[80] A. Islam, A. Ahmad, M.A. Laskar; A newly developed salicylanilide functionalized Amberlite XAD-16 chelating resin for use in preconcentration and determination of trace metal ions from environmental and biological samples; Anal. Methods 3 (2011) 20412048 .

[81] G.M. Willowed, R.G. Wuilloud, J.C.A. deWuilloud, R.A. Olsina, L.D. Martinez; On-line preconcentration and determination of chromium in parenteral solutions by flow injection-flame atomic absorption spectrometry; J. of Pharmaceutical and Biomedical Anal. 31 (2003) 117-124.

[82] Amran, M.B. Panggabean, A.S. Sulaeman, A. Rusnadi; Preparation of a Chelating Resin and its Application as a Preconcentration System for Determination of Cadmium in River Water by Flow Injection Analysis; spring 5 (2011) 531-536. 